\title{
Amine oxidase copper-containing 3 (AOC3) inhibition: a potential novel target for the management of diabetic retinopathy
}

\author{
David S. Boyer ${ }^{1}$, Joerg F. Rippmann², Michael S. Ehrlich³, Remko A. Bakker ${ }^{3}$, Victor Chong ${ }^{4}$ and \\ Quan Dong Nguyen ${ }^{5^{*}}$ (D)
}

\begin{abstract}
Background: Diabetic retinopathy (DR), a microvascular complication of diabetes, is the leading cause of visual impairment in people aged 20-65 years and can go undetected until vision is irreversibly lost. There is a need for treatments for non-proliferative diabetic retinopathy (NPDR) which, in comparison with current intravitreal (IVT) injections, offer an improved risk-benefit ratio and are suitable for the treatment of early stages of disease, during which there is no major visual impairment. Efficacious systemic therapy for NPDR, including oral treatment, would be an important and convenient therapeutic approach for patients and physicians and would reduce treatment burden. In this article, we review the rationale for the investigation of amine oxidase copper-containing 3 (AOC3), also known as semicarbazide-sensitive amine oxidase and vascular adhesion protein 1 (VAP1), as a novel target for the early treatment of moderate to severe NPDR. AOC3 is a membrane-bound adhesion protein that facilitates the binding of leukocytes to the retinal endothelium. Adherent leukocytes reduce blood flow and in turn rupture blood vessels, leading to ischemia and edema. AOC3 inhibition reduces leukocyte recruitment and is predicted to decrease the production of reactive oxygen species, thereby correcting the underlying hypoxia, ischemia, and edema seen in DR, as well as improving vascular function.

Conclusion: There is substantial unmet need for convenient, non-invasive treatments targeting moderately severe and severe NPDR to reduce progression and preserve vision. The existing pharmacotherapies (IVT corticosteroids and IVT anti-vascular endothelial growth factor-A) target inflammation and angiogenesis, respectively. Unlike these treatments, AOC3 inhibition is predicted to address the underlying hypoxia and ischemia seen in DR. AOC3 inhibitors represent a promising therapeutic strategy for treating patients with DR and could offer greater choice and reduce treatment burden, with the potential to improve patient compliance.
\end{abstract}

Keywords: Amine oxidase copper-containing 3, Semicarbazide-sensitive amine oxidase, Vascular adhesion protein 1, Non-proliferative diabetic retinopathy

\section{Background}

Diabetic retinopathy (DR) is a highly specific neurovascular complication affecting patients with type 1 and type 2 diabetes mellitus (DM) [1]. DR frequently affects both

${ }^{*}$ Correspondence: ndquan@stanford.edu

${ }^{5}$ Byers Eye Institute, Stanford University, Palo Alto, CA, USA

Full list of author information is available at the end of the article eyes, but may be asymptomatic during its early stages $[1$, 2]. As the disease progresses, an individual's vision may become blurred and their visual field restricted [2]. Ultimately, DR can progress to sight-threatening stages, the leading cause of new blindness among people of working age in developed countries [1]. Both tissue injury and vascular events contribute to vision loss in DR $[1,3]$, and 
neurodegeneration due to diabetes itself is an early event in the pathogenesis of DR [4].

Increased vascular permeability and/or capillary nonperfusion in DR leads to diabetic macular edema (DME) and macular ischemia, impairing the individual's central vision $[3,5]$. However, while the pathophysiology of DME and DR are highly interconnected, they may also develop independently [6]. Pre-retinal or vitreous hemorrhage stemming from angiogenesis is associated with damage to retinal neurons in the proliferative phase [3]. Moreover, vitreous contraction creates retinal distortion and tractional detachments, which can be severe and irreversible $[1,3]$.

Although the optimization of glycemic control, blood pressure, and serum lipid control is recommended to slow the progression of DR and decrease the risk of vision loss, many patients still develop proliferative diabetic retinopathy (PDR) [1]. While blindness in DR is largely preventable and moderate ocular abnormalities may even be reversible with systemic control (HbA1c) [7], treatment for DR is not usually administered until vision loss becomes apparent. Unfortunately, in the USA, only around $35-60 \%$ of patients with DM receive adequate DR screening $[8,9]$, and only $30-49 \%$ obtain appropriate follow-up care [10]. International guidelines advise that non-proliferative diabetic retinopathy (NPDR) should not be treated unless clinically significant macular edema is present [11]. PDR is characterized by pathologic vitreoretinal neovascularization, while NPDR comprises hallmark features of intraretinal hemorrhages, microaneurysms, lipid exudates, and capillary nonperfusion [12, 13]. DR severity is frequently graded in clinical studies using the Diabetic Retinopathy Severity Scale (DRSS); DRSS is derived from the ETDRS (Early Treatment Diabetic Retinopathy Study) and classifies mild, moderate, moderately severe, and severe NPDR as levels 35,43 , 47, and 53, respectively $[14,15]$ (Table 1 ).

\section{Current treatment options for moderately severe and severe NPDR}

While most patients with moderately severe or severe NPDR (DRSS level 47-53) do not receive treatment, these are not benign conditions and therapeutic intervention before the development of PDR, vitreous hemorrhage, or DME could reduce visual loss. The early detection of moderately severe to severe NPDR is especially important as the risk of vision loss increases with disease progression. The risk of developing early PDR after 1 year is $26.3 \%$ and $50.2 \%$ in patients with DRSS levels of 47 and 53, respectively [16]. Thus, regular screening can help to identify those patients at high risk of rapid progression who would benefit from treatment [1]. In the Phase 3 PANORAMA trial, 53\% of patients with severe
NPDR and $36 \%$ with moderately severe NPDR in the untreated control group developed vision-threatening events, compared with $15 \%$ of patients with severe NPDR and $8-10 \%$ of patients with moderately severe NPDR in the groups given intravitreal (IVT) treatment with the vascular endothelial growth factor A (VEGF-A) inhibitor aflibercept [18]. Treatment delays in patients who received a sham control before crossing over to ranibizumab in the extension phase of the RISE and RIDE studies also gained fewer ETDRS letters in best-corrected visual acuity score at Month 36 compared with baseline versus those who received ranibizumab throughout the studies [19].

Direct ophthalmic treatment options for NPDR are limited to pan-retinal photocoagulation (PRP), IVT corticosteroids, and IVT VEGF inhibitors. A Cochrane database systematic review of four trials of PRP and one trial of selective photocoagulation of non-perfusion areas concluded that laser photocoagulation is beneficial for PDR, but the authors noted the paucity of high-quality evidence confirming this conclusion [20]. However, the recent Diabetic Retinopathy Clinical Research Network (DRCR.net) Protocol S study showed that more patients with PDR treated with PRP had vitreous hemorrhages compared with patients receiving ranibizumab [21]. There is some evidence to show that PRP may reduce visual acuity in severe NPDR [22], and a systematic review and economic evaluation found insufficient evidence to recommend PRP in this patient group [23]. PRP sessions are uncomfortable and macular edema may develop or worsen after treatment [23, 24]. In addition, patients who undergo PRP treatment may experience a constricted visual field, reduced night vision, and macular or lens damage [24].

IVT implants of corticosteroids are licensed for the treatment of DME, but their use in DR remains limited as it may be associated with an increase in intraocular pressure and cataract development or worsening [25-29].

The VEGF inhibitors ranibizumab and aflibercept are approved by the US Food and Drug Administration (FDA) for the treatment of DR [30], and bevacizumab is widely used off-label for DME [25]. Brolucizumab, which is FDA approved for neovascular age-related macular degeneration [31], is also under investigation in PDR and DME [32, 33]. IVT VEGF inhibitor injections are invasive, expensive, and can be inconvenient to patients and their caregivers; at times, it may be necessary to treat each eye at a separate visit, thereby doubling treatment, travel, and recovery times, all of which contribute to patient, caregiver, and healthcare system burden [34, 35]. In addition, VEGF inhibitors do not improve ischemia or inflammation, do not provide neuroprotection, and continued VEGF inhibitor treatment is required 
to sustain any benefit to ischemia-related diabetic retinal dysfunction [35-38]. Furthermore, not all patients respond meaningfully to VEGF inhibitors [39-41]. In a study of DME among patients with NPDR, approximately three-quarters of eyes did not fully respond to aflibercept (108/141), bevacizumab (106/131), or ranibizumab $(111 / 151)$ at 2 years [41]. If appointments for VEGF inhibitor administration are missed (non-compliance), e.g. due to illness, DR could progress to more severe disease and may result in irreversible sight loss [37].

There is evidence that treatment with an additional drug with a different mode of action may reduce the effects of DR [42]. There are several barriers to compliance to IVT DR therapy and follow up, including lack of DR knowledge, DM end-organ damage, economic burden (both DR and DM), long appointment waiting times, and inability to attend appointments due to work or illness [43-45]. Given that compliance to IVT VEGF inhibitor therapy is suboptimal even in patients with agerelated macular degeneration and those with DME [46], compliance is likely to be even worse in less symptomatic patients with NPDR.

There is substantial unmet need for treatments that target moderately severe and severe NPDR before sight is compromised. If DR progresses to center-involving diabetic macular edema (CI-DME), patients will need long-term, invasive treatment to prevent further disease progression, which may not restore visual acuity [47]. The DRCR.net Protocol S study of 305 patients with PDR treated with PRP or VEGF inhibitor demonstrated that, at 6 months, the VEGF inhibitor ranibizumab failed to prevent neovascularization in $45 \%$ of eyes; however, a reduction in hemorrhage and vitrectomy were also identified in the anti-VEGF-treated patients compared with the PRP-treated patients [21]. The related DRCR.net Protocol V study showed that at 2 years, among 702 patients with CI-DME and good visual acuity (20/25 or better), there was no difference in visual acuity loss among those who received aflibercept, laser photocoagulation, or observation (no intervention) [48].

Encouraging patients to become more active in managing their disease is increasingly important, particularly in DM [49]. Although oral treatments for DR may be more convenient for patients than an IVT injection, they are not without possible drawbacks as patients may forget to take oral agents. In addition, compliance can be tracked more readily by physicians with an IVT injection, as the injection is administered in a clinic compared with selfadministration of oral medication at home. Furthermore, with an oral agent for NPDR, the potential for systemic effects, both good and bad, must be considered. Nevertheless, efficacious systemic therapy for NPDR, including oral treatment, may provide a convenient therapeutic approach for patients and physicians, and would reduce the treatment burden for patients and their caregivers.

\section{The role of inflammation in DR}

The neurovascular unit describes the interplay between blood vessel endothelial cells and pericytes, astrocytes, Müller cells, and neurons to establish the blood-retinal barrier (BRB), which controls nutrient flow to-and the removal of metabolic waste products from-the neural retina [3]. Müller glial cells are a significant source of inflammatory modulators, suggesting that retinal glial cell activation may play an early role in the onset of inflammatory processes that damage the retina as the disease progresses [50]. Elevated levels of inflammatory cytokines such as interleukin (IL)-1 $\beta$, IL-2, IL-4, IL-5, IL-6, IL-8, interferon $\gamma$ (IFN $\gamma$ ), and tumor necrosis factor $\alpha(\mathrm{TNF} \alpha)$ are found in the sera or vitreous or aqueous humor of patients with DR [51, 52]. Levels of IL-8 and TNF $\alpha$ are even higher among patients with NPDR compared with PDR [51]. Progressive retinal injury may reduce the integrity of the $\mathrm{BRB}$ leading to an accumulation of inflammatory and angiogenic mediators within the vitreous cavity [3]. The build-up of IL- $1 \beta$ and TNF $\alpha$ induces the expression of intracellular adhesion molecule 1 (ICAM1) and vascular cell adhesion molecule 1 (VCAM1), which attract leukocytes leading to leukostasis [53]. A further consequence of BRB impairment is the migration of macrophages into the neurosensory retina and/or an increased adherence to the vasculature [3].

\section{The potential role of corticosteroids in DR}

The importance of inflammation in the pathogenesis of DR provides a rationale for using corticosteroids as a treatment strategy-targeting the synthesis of key proinflammatory mediators such as IL-6, IL-8, TNF $\alpha$, ICAM1, and VEGF [54]. Several corticosteroids have been extensively studied in the treatment of DME, including triamcinolone acetonide (TA), the fluocinolone acetonide (FA) implant, and the dexamethasone (DEX) implant [26-29, $55,56]$. However, their clinical impact has been less thoroughly assessed in DR.

In an exploratory analysis of data from a DRCR.net Phase 3 trial in DME, IVT TA appeared to reduce the risk of DR progression compared with focal/grid photocoagulation alone [57]. A subsequent exploratory analysis in eyes without PDR at baseline suggested that the 3-year cumulative probability of retinopathy worsening may be higher in TA-treated eyes compared with those treated with the VEGF inhibitor ranibizumab [58]. However, in patients with PDR both treatments were associated with a reduced risk of PDR worsening compared with sham therapy [58]. More recently, a post hoc analysis of data from two Phase 3 DME trials suggested that another 
corticosteroid treatment, the FA implant, can delay the development of PDR and slow DR progression compared with sham control [59]. Finally, a retrospective cohort study of 60 patients with NPDR and DME found that treatment with the DEX implant could delay DR progression and improve DR severity over 24 months [60].

However, although these data are promising, prospective, randomized trials are lacking. In particular, studies comparing corticosteroid treatment with a VEGF inhibitor in patients with NPDR would be valuable. Furthermore, it is not known whether the current data on patients with DR and DME are applicable to those without DME. Known adverse events of corticosteroids, such as increased interocular pressure, glaucoma, and cataracts $[28,57,60]$, could be limiting their widespread use and restricting their use in patients with severe DR and/ or those who are pseudophakic.

\section{The role of $A O C 3$ protein in retinal inflammation and neovascularization}

Amine oxidase copper-containing 3 (AOC3), also known as semicarbazide-sensitive amine oxidase and vascular adhesion protein 1 (VAP1), is a membrane-bound adhesion protein that facilitates the binding of leukocytes to endothelial cells and their subsequent transmigration to sites of inflammation (Figs. 1 and 2) [61]. AOC3 is abundant in the activated endothelium of vascularized tissues, including the retina, kidney, and liver $[62,63]$, and is associated with vascular diseases and inflammatory conditions such as chronic kidney disease, chronic liver disease, and DM [61, 64-69]. AOC3 has previously been targeted for therapeutic intervention in autoimmune and inflammatory diseases, and several inhibitory compounds have been investigated over the past two decades [70-73]. Furthermore, AOC3 has been implicated as a possible candidate protein for mediating inflammation and oxidative stress in PDR [74], and may be important in the activation of early events in NPDR $[68,74,75]$. AOC3 is stored in intracellular vesicles and rapidly translocates to the luminal surface of endothelial cells during inflammation [76]. A soluble form of AOC3, which retains enzymatic activity, may also be released by shedding from the endothelial cell membrane following cleavage with matrix metalloproteinases (MMPs) (Fig. 1) [74]. AOC3 on the retinal endothelial cells mediates slow rolling, firm adhesion, and transmigration of leukocytes, triggering leukostasis $[61,77]$. Aldehydes, ammonia, and reactive oxygen species are released as a result of the interaction between AOC3 and its substrates, which contribute to inflammation and the accumulation of leukocytes, which rupture the blood vessel leading to ischemia [76]. Although soluble AOC3 does not mediate leukostasis, it contributes to the release of ammonia and reactive oxygen species (Fig. 2). Elevated levels of soluble AOC3 are found in type 1 and type $2 \mathrm{DM}$, correlating with complications such as end-stage renal disease, cardiovascular

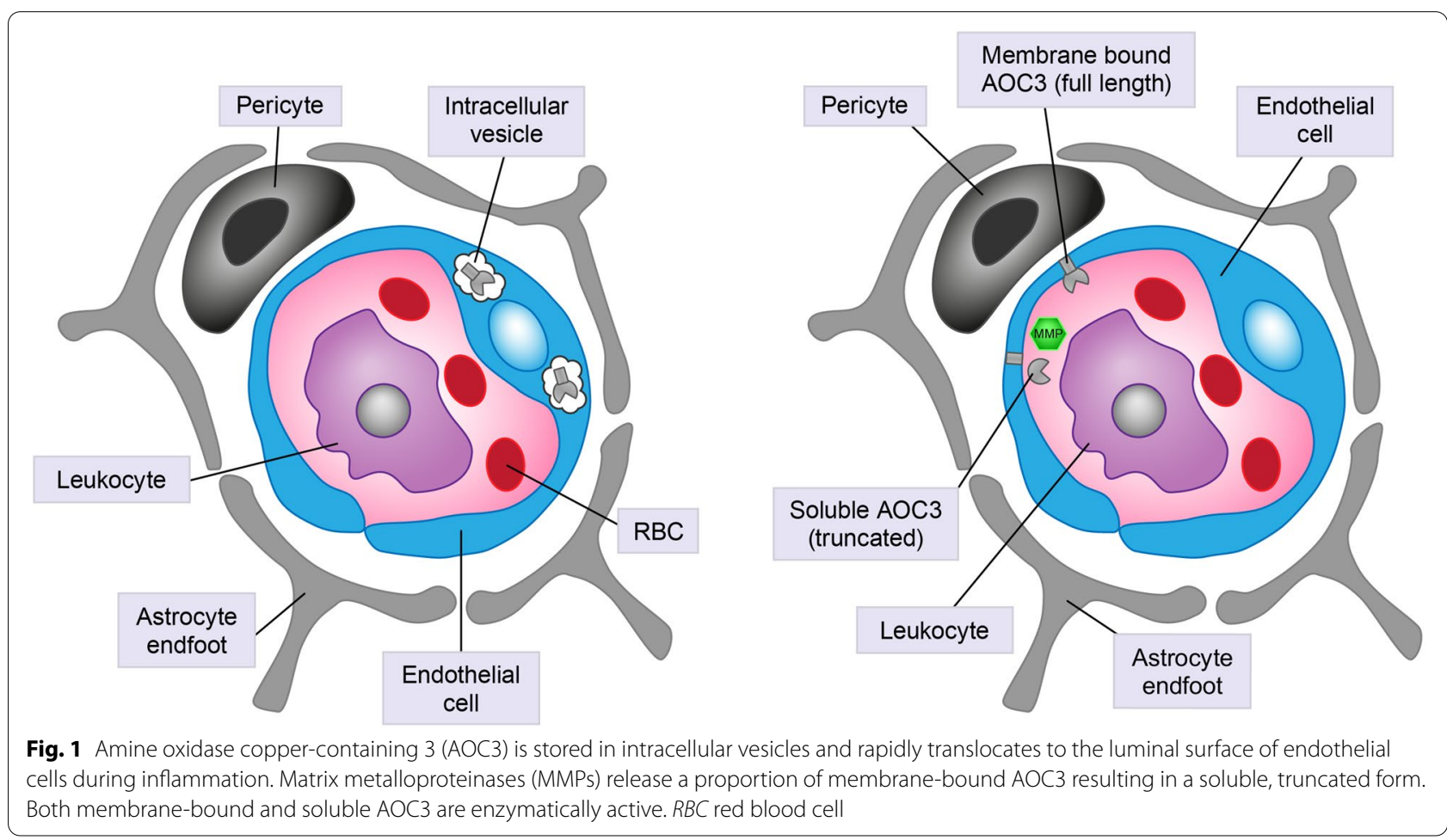




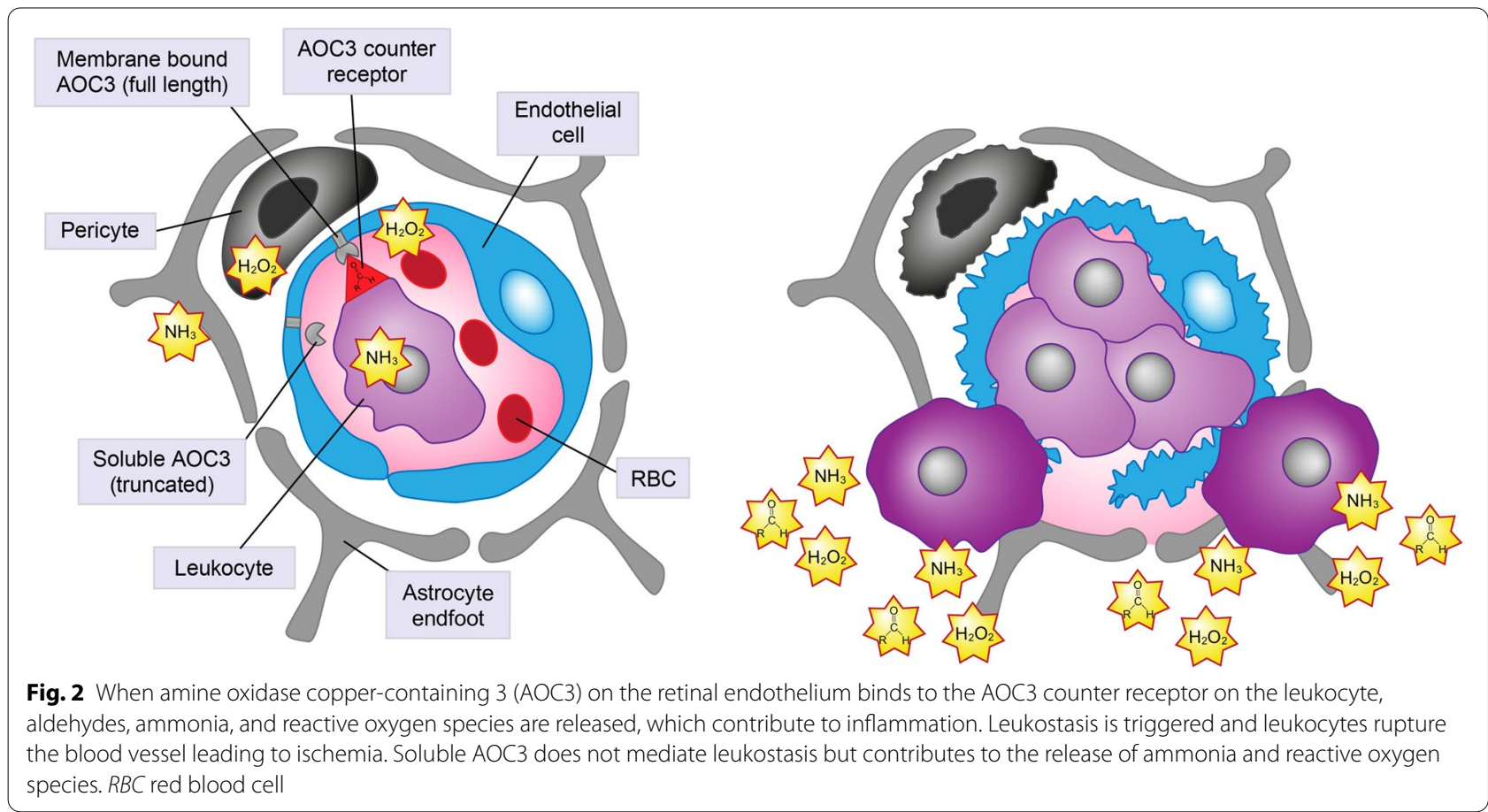

mortality, and DR [76, 78]. Furthermore, high levels of soluble AOC3 are predictive of cancer risk in patients with type 2 DM [79].

Inhibition and blocking of membrane-bound $\mathrm{AOC} 3$ were shown in preclinical models to reduce leukocyte recruitment and thereby transmigration $[61,80,81]$. A further consequence of reduced AOC3 enzymatic activity (of both full length and soluble forms) is a decrease in the oxidative deamination of primary amines, thus reducing the production of aldehydes, ammonia, and hydrogen peroxide [82], and ultimately reactive oxygen species (Fig. 3). Because the neurovascular unit of the retina is highly susceptible to hyperglycemic stress, inflammation, and reactive oxygen species, AOC3 inhibition may improve vascular function and lead to improved DRSS grading. Furthermore, leukocytes secrete proinflammatory cytokines, and therefore AOC3 blockade is predicted to reduce cytokine expression, macrophage recruitment, and choroidal neovascularization [81].

In addition, tissue ischemia and the resulting hypoxia in DR drive expression of VEGF-A [83]. VEGF-A promotes vascular permeability resulting in leakage of plasma through the blood-retinal barrier (BRB) and tissue edema through its interactions with VEGF receptor 2 (VEGFR-2) on vascular endothelial cells (Fig. 4) [83]. All currently available VEGF inhibitors bind to the receptor-binding site on VEGF-A, which inhibits interaction with, and activation of, VEGFR-2 on the surface of endothelial cells and, in turn, reduces angio- genesis, ultimately preventing progression and improving DRSS/ETDRS grading [84, 85]. Aflibercept and conbercept also act to scavenge placental growth factor (PIGF) $[85,86]$, which may lead to an increase in efficacy because PIGF can indirectly stimulate angiogenesis by binding to VEGFR-1, thus increasing the availability of VEGFA to activate VEGFR-2 [84]. However, VEGF inhibitors do not reduce inflammation or reactive oxygen species (Fig. 3). Instead, they act on the consequence of the disease-elevated secretion of VEGF-without addressing the actual cause of the disease. Consequently, such treatments are unlikely to result in sustained improvements in DR as they are not expected to ameliorate the underlying hypoxia or ischemia.

\section{Therapeutic targeting of AOC3 in DR}

To date, three orally administered AOC3 inhibitors have been investigated in DR and related conditions: ASP8232, RTU-1096, and BI 1467335 (formerly PXS4728A) (Table 2) [87-91]. Given that DR shares aspects of its pathogenesis with related conditions, such as DME, success in these related indications may support potential efficacy in DR.

Initial findings with ASP8232 were promising: pre-clinical studies demonstrated improved retinal and ocular hyperpermeability and reductions in surrogate markers of disease progression were observed in patients with type 2 DM $[87,88]$. However, in the VIDI (VAP1 inhibition in DME) study, ASP8232 failed to reduce central 


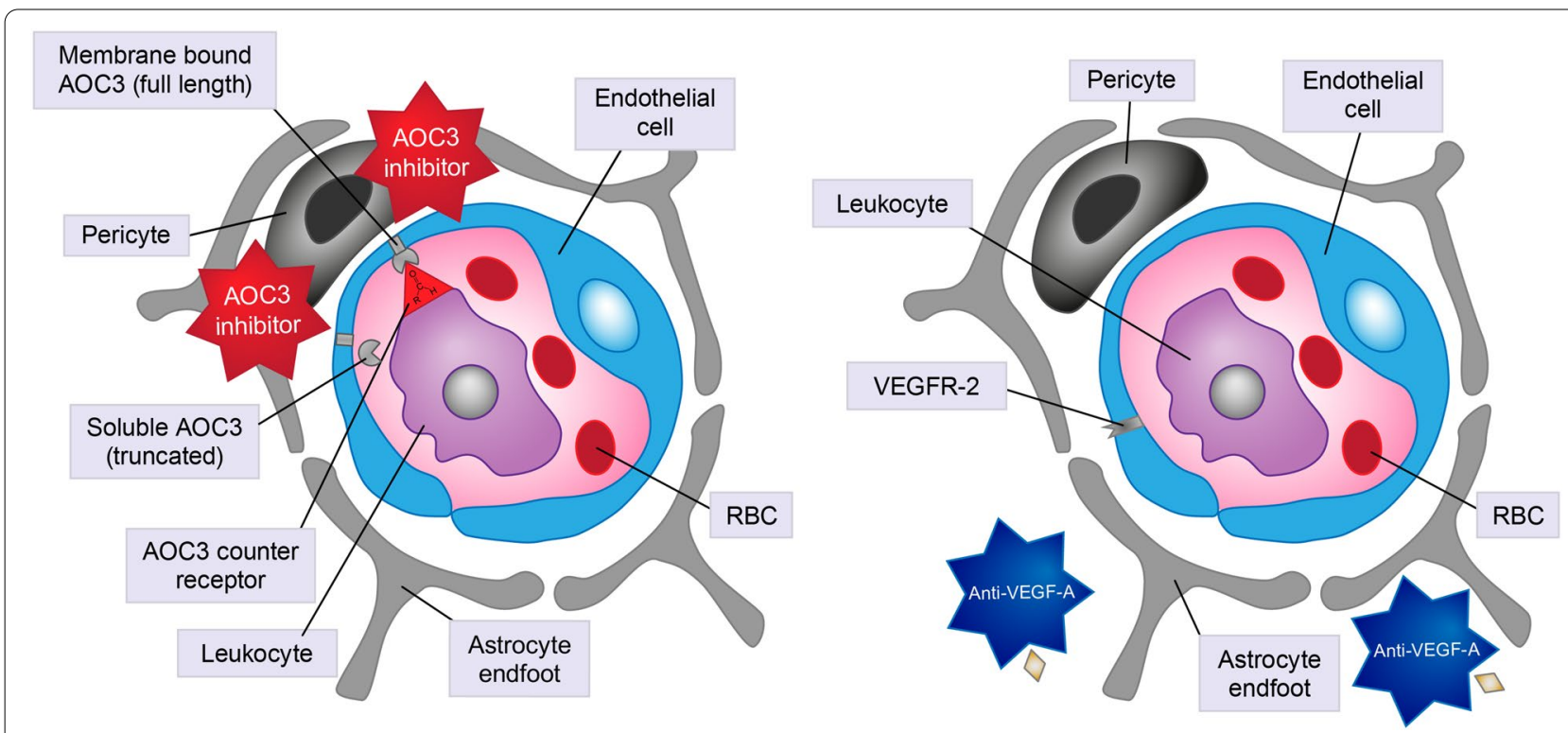

Fig. 3 Amine oxidase copper-containing 3 (AOC3) inhibition of membrane-bound form reduces leukocyte recruitment and thereby transmigration. A further consequence of reduced AOC3 enzymatic activity via inhibition of the membrane-bound and soluble forms is likely to be a decrease in the oxidative deamination of primary amines, thus reducing the production of aldehydes, ammonia, and hydrogen peroxide, and ultimately reducing reactive oxygen species. Vascular endothelial growth factor (VEGF) inhibitors bind to the receptor-binding site on VEGF-A, which inhibits interaction with, and activation of, VEGF receptor 2 (VEGFR-2) on the surface of endothelial cells, thereby reducing angiogenesis. RBC red blood cell

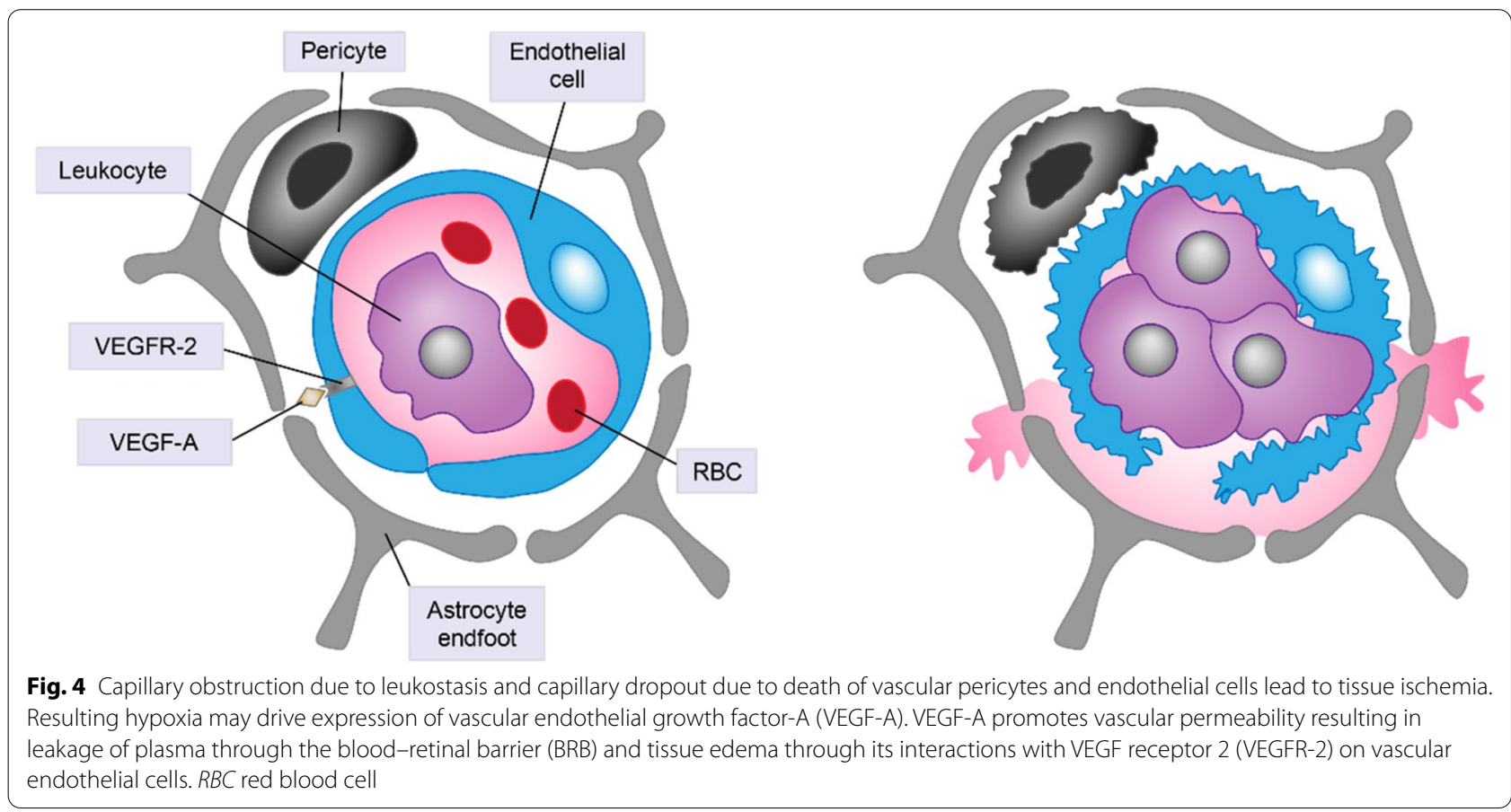

subfield thickness in patients with CI-DME when administered alone, and no additional benefit was observed when combined with ranibizumab [87]. The trial investigators postulated that the presence of significant
CI-DME may require inhibition of VEGF for clinical benefit, whereas DR could be reduced by AOC3 inhibition alone; they also suggested that alternative delivery modes may warrant further investigation [87]. It should 
Table 1 Correlation between disease severity levels according to the DRSS and ETDRS classification of DR

\begin{tabular}{|c|c|c|c|c|}
\hline Disease severity [16] & $\begin{array}{l}\text { Findings observable upon } \\
\text { dilated ophthalmoscopy [16] }\end{array}$ & ETDRS level equivalent [16] & Risk assessment [16] & $\begin{array}{l}\text { Prevalence of vision-related } \\
\text { difficulty [17] }\end{array}$ \\
\hline No apparent retinopathy & No abnormalities & Level 10: DR absent & & $\begin{array}{l}\text { Functional burden: } 20.2 \% \\
\text { Reading: } 11.7 \% \\
\text { Noticing objects to the } \\
\text { side: } 4.4 \%\end{array}$ \\
\hline Mild NPDR & Microaneurysms only & Level 20: Very mild NPDR & & \multirow{3}{*}{$\begin{array}{l}\text { Functional burden: } 20.4 \% \\
\text { Reading: } 8.5 \% \\
\text { Noticing objects to the } \\
\text { side: } 2.8 \%\end{array}$} \\
\hline \multirow[t]{2}{*}{ Moderate NPDR } & \multirow[t]{2}{*}{$\begin{array}{l}\text { More than just microaneurysms } \\
\text { but less than severe NPDR }\end{array}$} & $\begin{array}{l}\text { Levels 35, 43: Mild, moderate } \\
\text { NPDR less than 4:2:1 }\end{array}$ & $\begin{array}{l}\text { One-year risk for early PDR: } \\
5.4-11.9 \% \\
\text { One-year high-risk PDR: } \\
\quad 1.2-3.6 \%\end{array}$ & \\
\hline & & $\begin{array}{l}\text { Level 47: Moderately severe } \\
\text { NPDR less than 4:2:1 }\end{array}$ & $\begin{array}{l}\text { One-year risk for early PDR: } \\
26.3 \% \\
\text { One-year high-risk PDR: } 8.1 \%\end{array}$ & \\
\hline Severe NPDR & $\begin{array}{l}\text { No signs of PR but with any of } \\
\text { the following: } \\
\text { Extensive }(>20) \text { intraretinal } \\
\text { hemorrhages in each of the } \\
4 \text { quadrants } \\
\text { Definite venous beading in } \geq \\
2 \text { quadrants } \\
\text { Prominent IRMA in } \geq 1 \text { quadrant }\end{array}$ & $\begin{array}{l}\text { Levels 53A-53E: Severe to } \\
\text { very severe NPDR, 4:2:1 rule }\end{array}$ & $\begin{array}{l}\text { One-year risk for early PDR: } \\
\text { 50.2\% (severe NPDR) } \\
\text { One-year high-risk PDR: } \\
\text { 14.6\% (severe NPDR)-45.0\% } \\
\text { (very severe NPDR) }\end{array}$ & $\begin{array}{l}\text { Functional burden: } 48.5 \% \\
\text { Reading: } 33.3 \% \\
\text { Noticing objects to the } \\
\text { side: } 14.5 \%\end{array}$ \\
\hline PDR & $\begin{array}{l}\geq 1 \text { of the following: } \\
\text { Neovascularization } \\
\text { Vitreous/preretinal hemorrhage }\end{array}$ & $\begin{array}{l}\text { Levels } 61,65,71,75,81,85: \\
\text { PDR, high-risk PDR, very } \\
\text { severe, or advanced PDR }\end{array}$ & & \\
\hline Ungradable & & $\begin{array}{l}\text { Level 90: Cannot grade, } \\
\text { even sufficiently for level } \\
81 \text { or } 85\end{array}$ & & \\
\hline
\end{tabular}

DRSS Diabetic Retinopathy Severity Scale, DR diabetic retinopathy, ETDRS Eary Treatment Diabetic Retinopathy Study, IRMA intraretinal microvascular abnormalities, NPDR non-proliferative diabetic retinopathy, $P D R$ proliferative diabetic retinopathy

be noted that, based on non-linear mixed effects exposure-response pharmacodynamic modeling, the effects of ASP8232 are reversible, and acute effects at clinical doses in other indications (i.e. diabetic kidney disease) may have been artefactual [92].

In a mouse model of retinal inflammation, systemic administration of RTU-1096 reduced upregulation of ICAM1, an adhesion molecule for leukocytes, in the retina [91]. In Phase 1 trials that completed in 2015, oncedaily oral RTU-1096 was well tolerated at all tested doses and produced a sustained reduction in serum AOC3 in healthy male volunteers [93]. However, no trials of RTU1096 in DR or any other indication are currently registered on ClinicalTrials.gov, and it is unclear why further development was halted.

BI 1467335 inhibits tethering and rolling of neutrophils and reduces inflammation in animal models [89, 90]. The Phase 2a 'Randomized, double-masked, placebocontrolled exploratory study to evaluate safety, tolerability, pharmacodynamics, and pharmacokinetics of Orally administered BI 1467335 for 12 weeks with a 12 week follow up period in patients with Non-proliferative diabetic retinopathy without center-involved diabetic macular edema' (ROBIN) study of BI 1467335 completed in May 2020 [94]. The study met its primary endpoint in ocular safety (proportion of patients with any ocular adverse event up to 24 weeks) and BI 1467335 was well tolerated [95]. However, the study was unable to demonstrate a clear efficacy signal (proportion of patients with a $\geq 2$-step improvement in DRSS [from baseline to Week 12]) [95]; this may have been because the trial's duration (3 months) was too short to demonstrate a clear efficacy benefit. In addition, taking into account recent findings that suggest venous beading (VB) does not respond to treatment with anti-VEGF therapy in patients with NPDR [96], and that VB may differentiate ETDRS level 53 (severe NPDR) from ETDRS level 47 (moderately severe NPDR) in some patients [15], excluding patients with VB may have improved the efficacy signal in the ROBIN study. BI 1467335 was also being investigated in non-alcoholic steatohepatitis (NASH) [97]; the Phase 2a study met pre-specified targets for inhibiting plasma AOC3 activity compared with placebo and clinically relevant changes in NASH biomarkers [98]. However, based on the risk of drug-drug interactions with the compound in patients with NPDR and NASH, which were identified in another Phase 1 study [99], Boehringer Ingelheim 


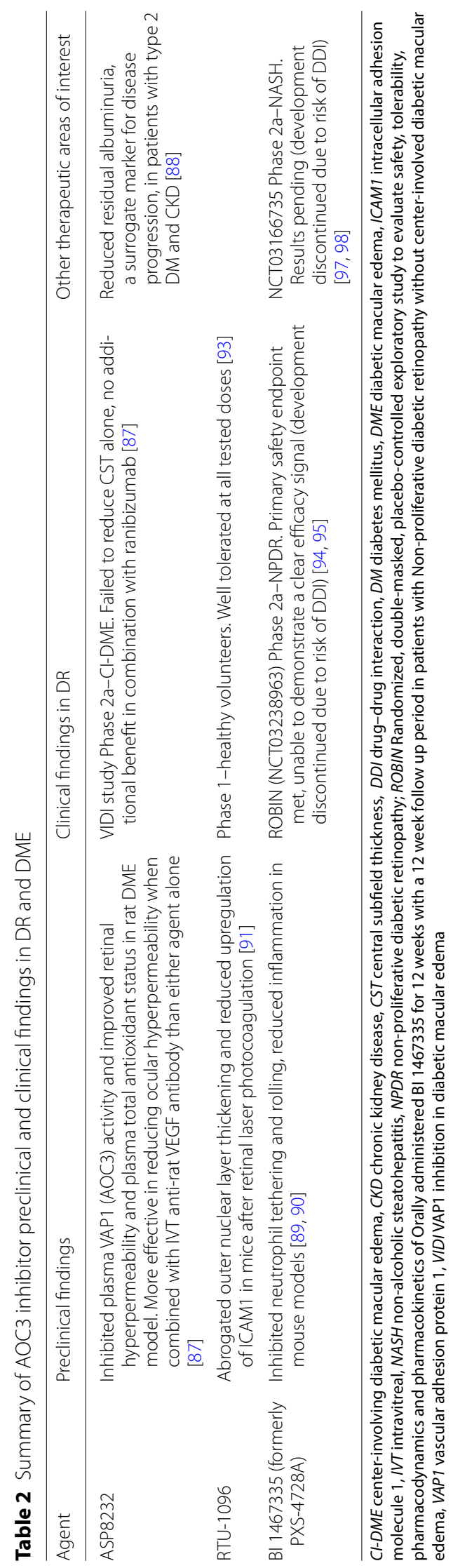


announced that the development of BI 1467335 has been discontinued in both indications $[95,98]$.

\section{Conclusion}

There is substantial unmet need for convenient, noninvasive treatments targeting moderately severe and severe NPDR. By treating the underlying cause of DR rather than its manifestations, resulting improvements may be more sustained. Unlike existing therapies that only target inflammation or angiogenesis, AOC3 inhibition is predicted to reduce leukostasis and reactive oxygen species, ultimately addressing the underlying hypoxia and ischemia seen in DR. Despite recent setbacks in clinical trials, AOC3 inhibition remains an attractive target due to the strength of preclinical data supporting the mechanism of action. The levels of AOC3 inhibition in these trials are likely to have varied among the different agents, and alternative AOC3 inhibitors may be more successful in the future. An orally administered treatment based on either an established or novel mechanism may still be a promising therapeutic strategy for treating patients with DR, with the aim of reducing treatment burden and improving patient compliance.

\begin{abstract}
Abbreviations
AOC3: Amine oxidase copper-containing 3; BRB: Blood-retinal barrier; CI-DME: Center-involving diabetic macular edema; CKD: Chronic kidney disease; CST: Central subfield thickness; DDI: Drug-drug interaction; DEX: Dexamethasone; DM: Diabetes mellitus; DME: Diabetic macular edema; DR: Diabetic retinopathy; DRSS: Diabetic Retinopathy Severity Scale; ETDRS: Early Treatment Diabetic Retinopathy Study; FA: Fluocinolone acetonide; FDA: Food and Drug Administration; ICAM1: Intracellular adhesion molecule 1; IFN: Interferon; IL: Interleukin; IRMA: Intraretinal microvascular abnormalities; IVT: Intravitreal; MMP: Matrix metalloproteinase; NASH: Non-alcoholic steatohepatitis; NPDR: Non-proliferative diabetic retinopathy; PDR: Proliferative diabetic retinopathy; PIGF: Placental growth factor; PRP: Pan-retinal photocoagulation; RBC: Red blood cell; TA: Triamcinolone acetonide; TNF: Tumor necrosis factor; VAP1: Vascular adhesion protein 1; VB: Venous beading;VCAM1: Vascular cell adhesion molecule 1; VEGF: Vascular endothelial growth factor; VEGFR: Vascular endothelial growth factor receptor.
\end{abstract}

\section{Acknowledgements}

The authors wish to acknowledge the contribution of Jochen Huber and Rolf Herrmann. Medical writing support was provided by Tom Priddle, DPhil, of OPEN Health Communications, funded by Boehringer Ingelheim.

\section{Authors' contributions}

All authors were involved in planning, drafting, and reviewing the manuscript. All authors approved the final published version and take responsibility for the content of the manuscript. All authors read and approved the final manuscript.

\section{Funding}

Medical writing support was funded by Boehringer Ingelheim.

\section{Availability of data and materials}

Not applicable.

\section{Ethics approval and consent to participate}

Not applicable.

\section{Consent for publication}

Not applicable.

\section{Competing interests}

DB is a consultant with Acucela, Alimera Sciences, Allegro, Bayer, EyePoint Pharmaceuticals, ONL Therapeutics, Oxurion, and Takeda; is a consultant and researcher with Adverum, Aerpio Pharmaceuticals, Allergan, Apellis, Boehringer Ingelheim, Chengdu Kanghong, Clearside Biomedical, Genentech/ Roche, Kodiak, Novartis, Regeneron, REGENXBIO, Roche, and Santen; and is a researcher with Aerie Pharmaceuticals, Gemini Therapeutics, Graybug Vision, IONIS Pharmaceuticals, Neurotech, Opthea, and Outlook Therapeutics. QDN serves on Scientific Advisory Boards for Aerie Pharmaceuticals, AsclepiX Therapeutics, EyePoint Pharmaceuticals, Bayer, Boehringer Ingelheim, Genentech/ Roche, Regeneron, and Santen. QDN is also the Coordinating Investigator of the ROBIN Study. RAB, VC, MSE, and JFR are employees of Boehringer Ingelheim.

\section{Author details}

${ }^{1}$ Retina-Vitreous Associates Medical Group, Los Angeles, CA, USA. ${ }^{2}$ CardioMetabolic Diseases Research, Boehringer Ingelheim Pharma, Biberach an der Riss, Germany. ${ }^{3}$ Boehringer Ingelheim Pharmaceuticals Inc., Ridgefield, CT, USA. ${ }^{4}$ Boehringer Ingelheim International $\mathrm{GmbH}$, Ingelheim Am Rhein, Germany. ${ }^{5}$ Byers Eye Institute, Stanford University, Palo Alto, CA, USA.

Received: 1 June 2020 Accepted: 19 February 2021

Published online: 12 April 2021

\section{References}

1. Solomon SD, Chew E, Duh EJ, Sobrin L, Sun JK, VanderBeek BL, et al. Diabetic retinopathy: A position statement by the American Diabetes Association. Diabetes Care. 2017:40:412-8.

2. American Academy of Ophthalmology. What is diabetic retinopathy? 2020. https://www.aao.org/eye-health/diseases/what-is-diabetic-retin opathy. Accessed 25 Jan 2021.

3. Antonetti DA, Klein R, Gardner TW. Diabetic retinopathy. N Engl J Med. 2012;366:1227-39.

4. Simo R, Stitt AW, Gardner TW. Neurodegeneration in diabetic retinopathy: Does it really matter? Diabetologia. 2018;61:1902-12.

5. Sun JK, Radwan SH, Soliman AZ, Lammer J, Lin MM, Prager SG, et al. Neural retinal disorganization as a robust marker of visual acuity in current and resolved diabetic macular edema. Diabetes. 2015;64:2560-70.

6. Schmidt-Erfurth U, Garcia-Arumi J, Bandello F, Berg K, Chakravarthy U, Gerendas BS, et al. Guidelines for the management of diabetic macular edema by the European Society of Retina Specialists (EURETINA). Ophthalmologica. 2017;237:185-222.

7. White NH, Waltman SR, Krupin T, Santiago JV. Reversal of abnormalities in ocular fluorophotometry in insulin-dependent diabetes after five to nine months of improved metabolic control. Diabetes. 1982;31:80-5.

8. Lee PP, Feldman ZW, Ostermann J, Brown DS, Sloan FA. Longitudinal rates of annual eye examinations of persons with diabetes and chronic eye diseases. Ophthalmology. 2003;110:1952-9.

9. Paz SH, Varma R, Klein R, Wu J, Azen SP. Noncompliance with vision care guidelines in Latinos with type 2 diabetes mellitus: The Los Angeles Latino Eye Study. Ophthalmology. 2006;113:1372-7.

10. Keenum Z, McGwin G Jr, Witherspoon CD, Haller JA, Clark ME, Owsley C. Patients' adherence to recommended follow-up eye care after diabetic retinopathy screening in a publicly funded county clinic and factors associated with follow-up eye care use. JAMA Ophthalmol. 2016;134:1221-8.

11. American Academy of Ophthalmology Preferred Practice Pattern Retina/ Vitreous Committee. Diabetic Retinopathy PPP 2019. 2019. https://www. aao.org/preferred-practice-pattern/diabetic-retinopathy-ppp. Accessed 25 Jan 2021.

12. Ishibazawa A, Nagaoka T, Yokota H, Takahashi A, Omae T, Song YS, et al. Characteristics of retinal neovascularization in proliferative diabetic retinopathy imaged by optical coherence tomography angiography. Invest Ophthalmol Vis Sci. 2016:57:6247-55.

13. Duh EJ, Sun JK, Stitt AW. Diabetic retinopathy: current understanding, mechanisms, and treatment strategies. JCI Insight. 2017;2. 
14. Fundus photographic risk factors for progression of diabetic retinopathy. ETDRS report number 12. Early Treatment Diabetic Retinopathy Study Research Group. Ophthalmology. 1991;98:823-33.

15. Wilkinson CP, Ferris FL 3rd, Klein RE, Lee PP, Agardh CD, Davis M, et al. Proposed international clinical diabetic retinopathy and diabetic macular edema disease severity scales. Ophthalmology. 2003;110:1677-82.

16. American Academy of Ophthalmology. International clinical diabetic retinopathy disease severity scale detailed table. 2002. http://www. icoph.org/dynamic/attachments/resources/diabetic-retinopathydetail.pdf. Accessed 25 Jan 2021.

17. Willis JR, Doan QV, Gleeson M, Haskova Z, Ramulu P, Morse L, et al. Vision-related functional burden of diabetic retinopathy across severity levels in the United States. JAMA Ophthalmol. 2017;135:926-32.

18. PR Newswire. One-year results from positive phase 3 EYLEA trial in diabetic retinopathy presented at Angiogenesis Symposium. 2019. https://www.prnewswire.com/news-releases/one-year-results-frompositive-phase-3-eylea-trial-in-diabetic-retinopathy-presented-atangiogenesis-symposium-300792822.html. Accessed 25 Jan 2021

19. Brown DM, Nguyen QD, Marcus DM, Boyer DS, Patel S, Feiner L, et al. Long-term outcomes of ranibizumab therapy for diabetic macular edema: The 36-month results from two phase III trials: RISE and RIDE. Ophthalmology. 2013;120:2013-22.

20. Evans JR, Michelessi M, Virgili G. Laser photocoagulation for proliferative diabetic retinopathy. Cochrane Database Syst Rev. 2014:Cd011234.

21. Sun JK, Glassman AR, Beaulieu WT, Stockdale CR, Bressler NM, Flaxel C, et al. Rationale and application of the Protocol $S$ anti-vascular endothelial growth factor algorithm for proliferative diabetic retinopathy. Ophthalmology. 2019;126:87-95.

22. Iwase T, Kobayashi M, Yamamoto K, Ra E, Terasaki H. Effects of photocoagulation on ocular blood flow in patients with severe non-proliferative diabetic retinopathy. PLOS ONE. 2017:12:e0174427.

23. Royle P, Mistry H, Auguste P, Shyangdan D, Freeman K, Lois N, et al. Panretinal photocoagulation and other forms of laser treatment and drug therapies for non-proliferative diabetic retinopathy: Systematic review and economic evaluation. Health Technol Assess. 2015;19:v-xxviii, $1-247$.

24. Deschler EK, Sun JK, Silva PS. Side-effects and complications of laser treatment in diabetic retinal disease. Semin Ophthalmol. 2014:29:290-300

25. Vaziri K, Schwartz SG, Relhan N, Kishor KS, Flynn HW Jr. New therapeutic approaches in diabetic retinopathy. Rev Diabet Stud. 2015;12:196-210.

26. Urbancic M, Gardasevic TI. Dexamethasone implant in the management of diabetic macular edema from clinician's perspective. Clin Ophthalmol. 2019;13:829-40.

27. Zur D, Iglicki M, Loewenstein A. The role of steroids in the management of diabetic macular edema. Ophthalmic Res. 2019:1-6.

28. Campochiaro PA, Brown DM, Pearson A, Chen S, Boyer D, Ruiz-Moreno J, et al. Sustained delivery fluocinolone acetonide vitreous inserts provide benefit for at least 3 years in patients with diabetic macular edema. Ophthalmology. 2012;119:2125-32.

29. Boyer DS, Yoon YH, Belfort R Jr, Bandello F, Maturi RK, Augustin AJ, et al. Three-year, randomized, sham-controlled trial of dexamethasone intravitreal implant in patients with diabetic macular edema. Ophthalmology. 2014;121:1904-14.

30. Sassalos TM, Paulus YM. Prefilled syringes for intravitreal drug delivery. Clin Ophthalmol. 2019;13:701-6.

31. Brolucizumab MA. First approval. Drugs. 2019;79:1997-2000.

32. NCT04278417. A 96-week, two-arm, randomized, single-masked, multicenter, phase III study assessing the efficacy and safety of brolucizumab $6 \mathrm{mg}$ compared to panretinal photocoagulation laser in patients with proliferative diabetic retinopathy. https://clinicaltrials.gov/ct2/show/ NCT04278417. Accessed 25 Jan 2021.

33. NCT04079231. A comparative double masked, two-arm, randomized, multicenter, phase IIIb study analyzing the efficacy and safety of brolucizumab versus aflibercept in patients with visual impairment due to diabetic macular edema (BUZZARD). https://clinicaltrials.gov/ct2/show/ NCT04079231. Accessed 25 Jan 2021.

34. Bolinger MT, Antonetti DA. Moving past anti-VEGF: Novel therapies for treating diabetic retinopathy. Int J Mol Sci. 2016;17:pii: E1498.
35. Zhao Y, Singh RP. The role of anti-vascular endothelial growth factor (antiVEGF) in the management of proliferative diabetic retinopathy. Drugs Context. 2018;7:212532

36. Sang DN, D'Amore PA. Is blockade of vascular endothelial growth factor beneficial for all types of diabetic retinopathy? Diabetologia. 2008:51:1570-3.

37. Wubben TJ, Johnson MW. Anti-VEGF therapy for diabetic retinopathy: Consequences of inadvertent treatment interruptions. Am J Ophthalmol. 2019:204:13-8

38. Mirshahi A, Roohipoor R, Lashay A, Mohammadi SF, Abdoallahi A, Faghihi $\mathrm{H}$. Bevacizumab-augmented retinal laser photocoagulation in proliferative diabetic retinopathy: A randomized double-masked clinical trial. Eur J Ophthalmol. 2008;18:263-9.

39. Dabir SS, Das D, Nallathambi J, Mangalesh S, Yadav NK, Schouten JS. Differential systemic gene expression profile in patients with diabetic macular edema: Responders versus nonresponders to standard treatment. Indian J Ophthalmol. 2014;62:66-73.

40. Kumluang S, Ingsrisawang L, Sangroongruangsri S, Chaikledkaew U, Ratanapakorn T, Ruamviboonsuk P, et al. A real-world study of effectiveness of intravitreal bevacizumab and ranibizumab injection for treating retinal diseases in Thailand. BMC Ophthalmol. 2019;19:82

41. Bressler SB, Liu D, Glassman AR, Blodi BA, Castellarin AA, Jampol LM, et al. Change in diabetic retinopathy through 2 years: Secondary analysis of a randomized clinical trial comparing aflibercept, bevacizumab, and ranibizumab. JAMA Ophthalmol. 2017;135:558-68.

42. Whitehead M, Osborne A, Widdowson PS, Yu-Wai-Man P, Martin KR. Angiopoietins in diabetic retinopathy: Current understanding and therapeutic potential. J Diabetes Res. 2019;2019:5140521.

43. Duan F, Liu Y, Chen X, Congdon N, Zhang J, Chen Q, et al. Influencing factors on compliance of timely visits among patients with proliferative diabetic retinopathy in southern China: A qualitative study. BMJ Open. 2017;7:e013578.

44. Chen AJ, Hwang V, Law PY, Stewart JM, Chao DL. Factors associated with non-compliance for diabetic retinopathy follow-up in an urban safety-net hospital. Ophthalmic Epidemiol. 2018;25:443-50.

45. Lu AJ, Chen AJ, Hwang V, Law PY, Stewart JM, Chao DL. Analysis of patient-reported barriers to diabetic retinopathy follow-up. Ophthalmic Surg Lasers Imaging Retina. 2019:50:99-105.

46. Weiss M, Sim DA, Herold T, Schumann RG, Liegl R, Kern C, et al. Compliance and adherence of patients with diabetic macular edema to intravitreal anti-vascular endothelial growth factor therapy in daily practice. Retina. 2018:38:2293-300.

47. Abu El-Asrar AM. Evolving strategies in the management of diabetic retinopathy. Middle East Afr J Ophthalmol. 2013;20:273-82.

48. Baker CW, Glassman AR, Beaulieu WT, Antoszyk AN, Browning DJ, Chalam $\mathrm{KV}$, et al. Effect of initial management with aflibercept vs laser photocoagulation vs observation on vision loss among patients with diabetic macular edema involving the center of the macula and good visual acuity: A randomized clinical trial. JAMA. 2019;321:1880-94.

49. American Diabetes Association. 5. Lifestyle management: Standards of medical care in diabetes_2019. Diabetes Care. 2019:42 Suppl 1:S46-60

50. Rubsam A, Parikh S, Fort PE. Role of inflammation in diabetic retinopathy. Int J Mol Sci. 2018:19.

51. Boss JD, Singh PK, Pandya HK, Tosi J, Kim C, Tewari A, et al. Assessment of neurotrophins and inflammatory mediators in vitreous of patients with diabetic retinopathy. Invest Ophthalmol Vis Sci. 2017;58:5594-603.

52. Wu H, Hwang DK, Song $X$, Tao Y. Association between aqueous cytokines and diabetic retinopathy stage. J Ophthalmol. 2017;2017:9402198.

53. Chen W, Esselman WJ, Jump DB, Busik JV. Anti-inflammatory effect of docosahexaenoic acid on cytokine-induced adhesion molecule expression in human retinal vascular endothelial cells. Invest Ophthalmol Vis Sci. 2005:46:4342-7.

54. Whitcup SM, Cidlowski JA, Csaky KG, Ambati J. Pharmacology of corticosteroids for diabetic macular edema. Invest Ophthalmol Vis Sci. 2018:59:1-12.

55. Campochiaro PA, Hafiz G, Shah SM, Bloom S, Brown DM, Busquets M, et al. Sustained ocular delivery of fluocinolone acetonide by an intravitreal insert. Ophthalmology. 2010;117(1393-9):e3.

56. Pearson PA, Comstock TL, Ip M, Callanan D, Morse LS, Ashton P, et al. Fluocinolone acetonide intravitreal implant for diabetic macular edema: A 
3-year multicenter, randomized, controlled clinical trial. Ophthalmology. 2011;118:1580-7.

57. Bressler NM, Edwards AR, Beck RW, Flaxel CJ, Glassman AR, Ip MS, et al. Exploratory analysis of diabetic retinopathy progression through 3 years in a randomized clinical trial that compares intravitreal triamcinolone acetonide with focal/grid photocoagulation. Arch Ophthalmol. 2009;127:1566-71.

58. Bressler SB, Qin H, Melia M, Bressler NM, Beck RW, Chan CK, et al. Exploratory analysis of the effect of intravitreal ranibizumab or triamcinolone on worsening of diabetic retinopathy in a randomized clinical trial. JAMA Ophthalmol. 2013;131:1033-40.

59. Wykoff CC, Chakravarthy U, Campochiaro PA, Bailey C, Green K, CunhaVaz J. Long-term effects of intravitreal $0.19 \mathrm{mg}$ fluocinolone acetonide implant on progression and regression of diabetic retinopathy. Ophthalmology. 2017;124:440-9.

60. Iglicki M, Zur D, Busch C, Okada M, Loewenstein A. Progression of diabetic retinopathy severity after treatment with dexamethasone implant: A 24-month cohort study the "DR-Pro-DEX Study." Acta Diabetol. 2018:55:541-7.

61. Noda K, Nakao S, Zandi S, Engelstadter V, Mashima Y, Hafezi-Moghadam A. Vascular adhesion protein-1 regulates leukocyte transmigration rate in the retina during diabetes. Exp Eye Res. 2009;89:774-81.

62. Almulki L, Noda K, Nakao S, Hisatomi T, Thomas KL, Hafezi-Moghadam A. Localization of vascular adhesion protein-1 (VAP-1) in the human eye. Exp Eye Res. 2010;90:26-32.

63. Salmi M, Kalimo K, Jalkanen S. Induction and function of vascular adhesion protein-1 at sites of inflammation. J Exp Med. 1993;178:2255-60.

64. Boomsma F, van den Meiracker AH, Winkel S, Aanstoot HJ, Batstra MR, Man in 't Veld AJ, et al. Circulating semicarbazide-sensitive amine oxidase is raised both in type I (insulin-dependent), in type II (non-insulindependent) diabetes mellitus and even in childhood type I diabetes at first clinical diagnosis. Diabetologia. 1999;42:233-7.

65. Boomsma F, Pedersen-Bjergaard U, Agerholm-Larsen B, Hut H, Dhamrait SS, Thorsteinsson B, et al. Association between plasma activities of semicarbazide-sensitive amine oxidase and angiotensin-converting enzyme in patients with type 1 diabetes mellitus. Diabetologia. 2005;48:1002-7.

66. Aalto K, Maksimow M, Juonala M, Viikari J, Jula A, Kahonen M, et al. Soluble vascular adhesion protein-1 correlates with cardiovascular risk factors and early atherosclerotic manifestations. Arterioscler Thromb Vasc Biol. 2012;32:523-32

67. Garpenstrand H, Ekblom J, Backlund LB, Oreland L, Rosenqvist U. Elevated plasma semicarbazide-sensitive amine oxidase (SSAO) activity in type 2 diabetes mellitus complicated by retinopathy. Diabet Med. 1999;16:514-21.

68. Gronvall-Nordquist JL, Backlund LB, Garpenstrand H, Ekblom J, Landin B, Yu PH, et al. Follow-up of plasma semicarbazide-sensitive amine oxidase activity and retinopathy in type 2 diabetes mellitus. J Diabetes Complications. 2001;15:250-6.

69. Li HY, Lin HA, Nien FJ, Wu VC, Jiang YD, Chang TJ, et al. Serum vascular adhesion protein-1 predicts end-stage renal disease in patients with type 2 diabetes. PLoS ONE. 2016;11:e0147981.

70. Dunkel P, Gelain A, Barlocco D, Haider N, Gyires K, Sperlagh B, et al. Semicarbazide-sensitive amine oxidase/vascular adhesion protein 1: Recent developments concerning substrates and inhibitors of a promising therapeutic target. Curr Med Chem. 2008;15:1827-39.

71. Smith DJ, Vainio PJ. Targeting vascular adhesion protein-1 to treat autoimmune and inflammatory diseases. Ann NY Acad Sci. 2007;1 110:382-8.

72. Bligt-Linden E, Pihlavisto M, Szatmari I, Otwinowski Z, Smith DJ, Lazar L, et al. Novel pyridazinone inhibitors for vascular adhesion protein-1 (VAP-1): Old target-new inhibition mode. J Med Chem. 2013;56:9837-48.

73. Inoue T, Morita M, Tojo T, Nagashima A, Moritomo A, Imai K, et al. Synthesis and SAR study of new thiazole derivatives as vascular adhesion protein-1 (VAP-1) inhibitors for the treatment of diabetic macular edema: Part 2. Bioorg Med Chem. 2013;21:2478-94.

74. Murata M, Noda K, Fukuhara J, Kanda A, Kase S, Saito W, et al. Soluble vascular adhesion protein-1 accumulates in proliferative diabetic retinopathy. Invest Ophthalmol Vis Sci. 2012;53:4055-62.

75. O'Sullivan J, Unzeta M, Healy J, O'Sullivan MI, Davey G, Tipton KF. Semicarbazide-sensitive amine oxidases: Enzymes with quite a lot to do. Neurotoxicology. 2004;25:303-15.
76. Salmi M, Jalkanen S. Vascular adhesion protein-1: A cell surface amine oxidase in translation. Antioxid Redox Signal. 2019;30:314-32.

77. Stolen CM, Marttila-Ichihara F, Koskinen K, Yegutkin GG, Turja R, Bono P, et al. Absence of the endothelial oxidase AOC3 leads to abnormal leukocyte traffic in vivo. Immunity. 2005;22:105-15.

78. Yoshikawa N, Noda K, Shinoda H, Uchida A, Ozawa Y, Tsubota K, et al. Serum vascular adhesion protein-1 correlates with vascular endothelial growth factor in patients with type II diabetes. J Diabetes Complications. 2013:27:162-6

79. Yu TY, Li HY, Jiang YD, Chang TJ, Wei JN, Lin CM, et al. Serum vascular adhesion protein-1 level predicts risk of incident cancers in subjects with type II diabetes. Cancer Epidemiol Biomarkers Prev. 2014;23:1366-73.

80. Merinen M, Irjala H, Salmi M, Jaakkola I, Hanninen A, Jalkanen S. Vascular adhesion protein-1 is involved in both acute and chronic inflammation in the mouse. Am J Pathol. 2005;166:793-800.

81. Noda K, She H, Nakazawa T, Hisatomi T, Nakao S, Almulki L, et al. Vascular adhesion protein-1 blockade suppresses choroidal neovascularization. FASEB J. 2008;22:2928-35.

82. Murata M, Noda K, Kawasaki A, Yoshida S, Dong Y, Saito M, et al. Soluble vascular adhesion protein-1 mediates spermine oxidation as semicarbazide-sensitive amine oxidase: Possible role in proliferative diabetic retinopathy. Curr Eye Res. 2017:42:1674-83.

83. Penn JS, Madan A, Caldwell RB, Bartoli M, Caldwell RW, Hartnett ME. Vascular endothelial growth factor in eye disease. Prog Retin Eye Res. 2008;27:331-71.

84. Nguyen QD, De Falco S, Behar-Cohen F, Lam WC, Li X, Reichhart N, et al. Placental growth factor and its potential role in diabetic retinopathy and other ocular neovascular diseases. Acta Ophthalmol. 2018;96:e1-9.

85. Papadopoulos N, Martin J, Ruan Q, Rafique A, Rosconi MP, Shi E, et al. Binding and neutralization of vascular endothelial growth factor (VEGF) and related ligands by VEGF Trap, ranibizumab and bevacizumab. Angiogenesis. 2012;15:171-85.

86. Zhou AY, Bai YJ, Zhao M, Yu WZ, Li XX. KH902, a recombinant human VEGF receptor fusion protein, reduced the level of placental growth factor in alkali burn induced-corneal neovascularization. Ophthalmic Res. 2013:50:180-6.

87. Nguyen QD, Sepah YJ, Berger B, Brown D, Do DV, Garcia-Hernandez A, et al. Primary outcomes of the VIDI study: Phase 2, double-masked, randomized, active-controlled study of ASP8232 for diabetic macular edema. Int J Retina Vitreous. 2019;5:28.

88. de Zeeuw D, Renfurm RW, Bakris G, Rossing P, Perkovic V, Hou FF, et al. Efficacy of a novel inhibitor of vascular adhesion protein-1 in reducing albuminuria in patients with diabetic kidney disease (ALBUM): A randomised, placebo-controlled, phase 2 trial. Lancet Diabetes Endocrinol. 2018;6:925-33.

89. Schilter HC, Collison A, Russo RC, Foot JS, Yow TT, Vieira AT, et al. Effects of an anti-inflammatory VAP-1/SSAO inhibitor, PXS-4728A, on pulmonary neutrophil migration. Respir Res. 2015;16:42.

90. Jarnicki AG, Schilter H, Liu G, Wheeldon K, Essilfie AT, Foot JS, et al. The inhibitor of semicarbazide-sensitive amine oxidase, PXS-4728A, ameliorates key features of chronic obstructive pulmonary disease in a mouse model. Br J Pharmacol. 2016;173:3161-75.

91. Matsuda T, Noda K, Murata M, Kawasaki A, Kanda A, Mashima Y et al. Vascular adhesion protein-1 blockade suppresses ocular inflammation after retinal laser photocoagulation in mice. Invest Ophthalmol Vis Sci. 2017:58:3254-61.

92. Hoefman S, Snelder N, van Noort M, Garcia-Hernandez A, Onkels H, Larsson TE, et al. Mechanism-based modeling of the effect of a novel inhibitor of vascular adhesion protein-1 on albuminuria and renal function markers in patients with diabetic kidney disease. J Pharmacokinet Pharmacodyn. 2020. https://doi.org/10.1007/s10928-020-09716-x

93. Business Wire. R-Tech Ueno: Announcement on completion of the phase I single-dose clinical trial for the novel VAP-1 inhibitor RTU-1096. 2015 https://www.businesswire.com/news/home/20150524005057/en/RTech-Ueno-Announcement-Completion-Phase-Single-Dose-Clinical. Accessed 25 Jan 2021.

94. NCT03238963. A randomized, double-masked, placebo-controlled exploratory study to evaluate safety, tolerability, pharmacodynamics and pharmacokinetics of orally administered BI 1467335 for 12 weeks with a 12 week follow up period in patients with non-proliferative diabetic 
retinopathy without center-involved diabetic macular edema (ROBIN Study). https://clinicaltrials.gov/ct2/show/NCT03238963. Accessed 25 Jan 2021.

95. Boehringer Ingelheim. Boehringer Ingelheim discontinues development of BI 1467335 for Diabetic Retinopathy. 2020. https://www.boehringeringelheim.com/press-release/discontinuation-bi-1467335-diabetic-retin opathy. Accessed 25 Jan 2021

96. Pearce E, Chong V, Sivaprasad S. Aflibercept reduces retinal hemorrhages and intravitreal microvascular abnormalities but not venous beading: secondary analysis of the CLARITY study. Ophthalmol Retina. 2020;4:689-94.

97. NCT03166735. A multi-centre, double-blind, parallel-group, randomised, placebo controlled phase II a study to investigate safety, tolerability, pharmacodynamics, and pharmacokinetics of different doses of orally administered BI 1467335 during a 12-week treatment period compared to placebo in patients with clinical evidence of NASH. https://clinicaltrials. gov/ct2/show/NCT03166735. Accessed 25 Jan 2021.
98. Boehringer Ingelheim. Boehringer Ingelheim discontinues development of BI 1467335 for NASH. 2019. https://www.boehringer-ingelheim.us/ press-release/boehringer-ingelheim-discontinues-development-bi1467335-nash. Accessed 25 Jan 2021.

99. NCT03927209. A phase I, open-label, positron emission tomography study in healthy male subjects to explore the inhibition of monoamine oxidase B in the brain after multiple oral doses of BI 1467335 (non-randomized, open-label, parallel-group study). https://clinicaltrials.gov/ct2/ show/NCT03927209. Accessed 25 Jan 2021.

\section{Publisher's Note}

Springer Nature remains neutral with regard to jurisdictional claims in published maps and institutional affiliations.
Ready to submit your research? Choose BMC and benefit from:

- fast, convenient online submission

- thorough peer review by experienced researchers in your field

- rapid publication on acceptance

- support for research data, including large and complex data types

- gold Open Access which fosters wider collaboration and increased citations

- maximum visibility for your research: over $100 \mathrm{M}$ website views per year

At BMC, research is always in progress.

Learn more biomedcentral.com/submissions 